\title{
FORMAÇÃO DOCENTE DO CURSO DE PEDAGOGIA DA UNESC, COM ENFÂSE NO ESTÁGIO SUPERVISIONADO OBRIGATÓRIO
}

\section{TEACHER'S FORMATION AT UNESC PEDAGOGY DEGREE WITH EMPHASIS AT PRACTICUM}

\author{
Morgana Fernandes Batista ${ }^{1}$ \\ Ricardo Luiz de Bittencourt ${ }^{2}$
}

\section{RESUMO}

A formação de professores é um processo complexo, uma vez que se entrelaçam diversos fatores, dentre os quais o estágio obrigatório. O objetivo geral desta pesquisa é "analisar a contribuição do Estágio Supervisionado Obrigatório para formação docente na perspectiva do licenciando do curso de licenciatura em Pedagogia da UNESC". Alguns autores como Nóvoa (2009), Pimenta (2002) e Tardif (2002), entre outros, apontam perspectivas atuais de formação de professores. Já Pimenta e Lima (2012), Pimenta (2005), Moraes (2012) entre outros destacam o estágio supervisionado obrigatório como atividade formativa. Desenvolvemos a coleta de dados a partir da aplicação de um questionário com 15 (quinze) acadêmicos que cursavam a $8^{\text {a }}$ fase do curso de licenciatura em Pedagogia da UNESC no ano de 2016-1, no município de Criciúma-SC. As análises dos dados produzidas indicam que o estágio obrigatório tem forte impacto na formação dos licenciados em Pedagogia. Os sujeitos pesquisados indicam que o estágio supervisionado contribui para a escolha da modalidade em que querem atuar. Afirmam que este é o momento de fazer a articulação da teoria na prática e que este se constitui como atividade formativa por auxiliá-los em sua formação por inseri-los dentro da escola e da sala de aula para que seja possível observar a realidade escolar e, assim, refletir sobre sua prática pedagógica.

PALAVRAS-CHAVE: Formação de professores. Estágio Supervisionado. Pedagogia. Teoria x Prática.

\begin{abstract}
Teacher training is a complex process since intertwine several factors, among which, the compulsory stage. The main objective is to "examine the contribution of the supervised internship required for teacher training in the perspective of the licensing course degree in pedagogy of UNESC". Some authors like Nóvoa (2009), Pimenta (2002), Tardif (2002) among others point current perspectives of teacher training, since Pimenta and Lima (2012), Pimenta (2005), Moraes (2012) and others highlight the supervised internship required as formative activity. We develop data collection from the application of a questionnaire with 15 (fifteen) scholars who attended the 8th stage of the course of degree in pedagogy of UNESC in the year 2016-1, in the municipality of Criciúma. The analysis of the data produced indicate that the compulsory stage has a strong impact on the training of graduates in

\footnotetext{
${ }^{1}$ Graduada em Pedagogia. Participante do Grupo de Pesquisa Políticas, Saberes e Práticas de Formação de Professores. rlb@unesc.net.

2 Doutor em Educação. Coordenador Adjunto do Curso de Pedagogia da UNESC. Coordenador do Pibid Subprojeto Interdisciplinar. Líder do Grupo de Pesquisa Políticas, Saberes e Práticas de Formação de Professores. Pesquisador do GEU UNESC.rlb@unesc.net.
}

Saberes Pedagógicos, Criciúma, v. 1, n², julho/dezembro 2017.- Curso de Pedagogia- UNESC 


\section{SABERES PEDAGÓGICOS}

Revista do Curso de Graduação de Pedagogia - Unesc

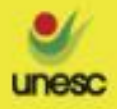

Hretices Acadonica

do Humaridaces.

pedagogy. The subjects surveyed indicate that the supervised internship contributes to the choice of the mode in which you want to perform. Claim that this is the time to do the articulation of theory in practice and that it constitutes as formative activity by assists you in your training by inserts it ins* the school and the classroom so you can observe the reality and thus reflect about their pedagogival practice.

KEYWORDS: Training of teachers; Supervised Apprenticeship; Pedagogy; Practical X Theory. 1 INTRODUÇÃ̃O

Este artigo trata de uma pesquisa sobre a formação de professores e do estágio supervisionado obrigatório como atividade formativa dos licenciandos em Pedagogia com a intenção de perceber as contribuições do estágio supervisionado no curso de formação de professores, pois além de promover um contato direto com a prática educacional contribui para uma inter-relação entre a teoria e a prática.

A escolha deste tema surgiu em uma discussão na $6^{\text {a }}$ fase do curso de licenciatura em Pedagogia-UNESC, na disciplina de Estágio Supervisionado II (Séries Iniciais), com a leitura do texto "Estágio e Docência", de Pimenta e Lima (2012). Esta leitura nos trouxe questões sobre o Estágio Supervisionado Obrigatório, acerca da qualificação do profissional com relação à teoria e à prática, se o estágio aproxima o docente em formação da realidade encontrada na sala de aula, se os professores titulares aceitam que o docente em formação aplique seus planos ou projetos em sala de aula.

Perante as inquietações optamos por fazer uma investigação através do seguinte problema: "Qual a contribuição do Estágio Supervisionado Obrigatório para a formação docente na perspectiva do licenciando da $8^{\text {a }}$ fase do curso de licenciatura em Pedagogia da UNESC". Para melhor organizar esta pesquisa procurou-se problematizar: que estudos e pesquisas tratam da formação de professores e do estágio supervisionado obrigatório como atividade formativa? Como o estágio supervisionado obrigatório se constitui como atividade formativa? Quais as percepções dos licenciados em Pedagogia sobre o estágio supervisionado obrigatório? Qual a contribuição do estágio supervisionado obrigatório para a formação docente e profissional?

Com os objetivos específicos buscou-se identificar estudos e pesquisas que tratam da formação de professores e do estágio como atividade formativa; perceber o estágio supervisionado obrigatório como atividade formativa; descrever as percepções dos licenciados

Saberes Pedagógicos, Criciúma, v. 1, n², julho/dezembro 2017.- Curso de Pedagogia- UNESC 
Revista do Curso de Graduação de Pedagogia - Unesc

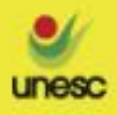

Unathes acodenis

unesc

al hiumeridatec.

em Pedagogia sobre o estágio supervisionado obrigatório; apresentar as contribuições do estágio supervisionado obrigatório para a formação docente e profissional.

Este artigo estrutura-se nas seguintes seções: primeiro apresentamos as perspectivas atuais de formação de professores, iniciando com a formação docente na perspectiva de autores que debatem este assunto, como Nóvoa (1992; 2009), Pimenta (2002), Tardif (2002), Ferreira e Carvalho (2006). A próxima seção trata das diretrizes que regulamentam o estágio supervisionado obrigatório, também são trazidas informações de autores e pesquisadores sobre o estágio supervisionado obrigatório, sendo assim, dialogamos com autores como: Pimenta; Lima (2012), Pimenta (2002; 2006), Freire (2001), Lima (2012), Moraes (2012), entre outros.

Em seguida apresentamos a metodologia da pesquisa e análise de dados, visando encontrar contribuição para a formação docente junto ao estágio supervisionado obrigatório. $\mathrm{E}$ por fim apresentamos a conclusão, à luz do nosso referencial teórico, e as referências bibliográficas que deram suporte a este artigo.

\section{PERSPECTIVAS ATUAIS DE FORMAÇÃO DE PROFESSORES}

Falar em formação nos remete à ação de formar-se, que de acordo com o Dicionário On-line Michells (2016) "é conceber ou receber certificado de conclusão de curso”. Quando abordamos o tema formação de pedagogos, pensamos em um curso em que a maioria dos sujeitos inseridos é de mulheres, essa ideia nasceu frente às Escolas Normalistas, as quais se destinavam a ensinar as tarefas doméstica e educativa. Contudo, ainda hoje “[...] $\mathrm{Na}$ educação infantil, as mulheres ocupam 98,5\% das funções docentes. [...] a presença de homens na docência nesses níveis ainda é rara e que são poucos os que ousam ingressar e permanecer nessa atividade profissional". (FERREIRA; CARVALHO, 2006, p. 144).

Esta seção tem por objetivo apresentar as principais contribuições dos teóricos que descrevem a perspectiva da formação dos professores como atividade formativa. E para isso utilizamos os seguintes teóricos: Nóvoa (1992; 2009), Pimenta (2002) e Tardif (2002). Esses teóricos foram escolhidos por se tratar de autores que pesquisam sobre o que há de mais atual sobre a formação de professores, assim também por terem sido apresentados a mim enquanto docente no processo de formação.

Saberes Pedagógicos, Criciúma, v. 1, n² , julho/dezembro 2017.- Curso de Pedagogia- UNESC 


\title{
2.1 A formação docente na perspectiva de Nóvoa, Pimenta e Tardif
}

Nóvoa (1992, p. 15) traz uma trajetória da formação de professores em seu texto “O processo histórico de profissionalização do professorado" e alguns apontamentos teóricos. Entre eles, "quando o professorado se constituiu em profissão, foi quando houve a intervenção do Estado, que substituiu a igreja como entidade de ensino".

Segundo Nóvoa (2009, p. 6), conforme vamos transitando pelo campo de discentes para docentes em formação isso implica "consolidar as bases de uma formação que tenha como referência lógica de acompanhamento, de formação-em-situação, de análise da prática e de integração na cultura profissional docente". Ou seja, para uma formação com eficácia devemos sempre buscar ter uma boa relação de companheirismo e de comunicação das práticas pedagógicas no que diz respeito ao ensino e aprendizagem.

Sendo assim, Nóvoa (2009, p. 6) afirma que passamos por alguns momentos:

\begin{abstract}
Um momento particularmente sensível na formação de professores é a fase de indução profissional, isto é, os primeiros anos de exercício docente. Grande parte da nossa vida profissional joga-se nestes anos iniciais e na forma como nos integramos na escola e no professorado. Neste sentido, este momento deve ser organizado como parte integrante do programa de formação em articulação com a licenciatura [...].
\end{abstract}

Mesmo com toda a dificuldade encontrada no início da carreira é importante que a categoria de novos professores se unifique para combater alguns métodos tradicionalistas enraizados na educação, ou seja, que consigam impor suas ideias e fazer a diferença no mercado de trabalho e que não se deixem cair em um círculo vicioso, como não trazendo propostas educativas diferenciadas, tais como fazer suas aulas utilizando outros espaços, entre outras didáticas, oportunizando a seus alunos ampliarem seus conhecimentos.

Nóvoa (1992, p. 1) relaciona a “[...] formação de professores com o desenvolvimento pessoal (produzir a vida do professor), com o desenvolvimento profissional (produzir a profissão docente) e com o desenvolvimento organizacional (produzir a escola)".

Contudo, a formação de professores avança com constantes transformações, e cabe aos professores estarem sempre questionando sua ação e, assim, tornarem-se professores

Saberes Pedagógicos, Criciúma, v. 1, n², julho/dezembro 2017.- Curso de Pedagogia- UNESC 


\section{SABERES PEDAGÓGICOS}

Revista do Curso de Graduação de Pedagogia - Unesc

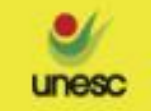

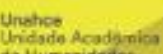

Co Humaridadec:

reflexivos sobre suas próprias práticas. Isso implica, de acordo com Dominice (1986 apud NÓVOA, 1992, p. 13), que "a formação vai e vem, avança e recua, construindo-se num processo de relação ao saber e ao conhecimento que se encontra no cerne da identidade pessoal”.

Como futuros professores, segundo Nóvoa (2009, p. 7), temos que "criar hábitos de reflexão e de autorreflexão que são essenciais numa profissão que não se esgota em matrizes científicas ou mesmo pedagógicas, e que se define, inevitavelmente, a partir de referências pessoais [...]”. Ou seja, devemos ser professores pesquisadores da nossa própria prática, e para que não venhamos a esquecer do dia a dia é necessário criarmos o hábito de anotar o decorrer de toda aula. Ser professor implica compreender os sentidos da instituição escolar e integrar sua profissão, aprendendo a compartilhar informações com os colegas com mais experiência, e a busca por formações qualificadas, para a construção do conhecimento profissional.

Na perspectiva de Selma Garrido Pimenta, o professor constrói e fundamenta o saber articulando aos outros saberes, ou seja, o saber específico que lhe compete, o pedagógico e as trocas de experiências, e essas mudam de acordo com o que lhe é oferecido nas escolas, os desafios a serem cumpridos, sendo assim, o professor sempre está em processo de formação.

Contudo, Pimenta (2002, p. 16) coloca que "pesquisas recentes têm se voltado à análise da prática docente [...]. Em decorrência, tem se colocado em foco a formação - a inicial e a contínua". Entende-se que a formação inicial é a que permite o exercício de uma profissão, e pode ser em nível médio, técnico e de graduação. Já a formação continuada é um modelo de formação que permite o aperfeiçoamento e a especialização da formação inicial.

A autora enfatiza que a formação do professor não tem ponto de chegada, ou seja, ela inicia-se com a formação inicial, em que se espera que forme o professor, e tem continuidade com as formações contínuas, com cursos de aperfeiçoamento e atualizações de ensino, contudo, Pimenta (2002, p. 16) defende que as novas pesquisas apresentadas se referem à "identidade profissional do professor".

De acordo com Pimenta (2002, p. 19): 


\section{SABERES PEDAGÓGICOS}

Revista do Curso de Graduação de Pedagogia - Unesc

Uma identidade profissional se constrói, pois, a partir da significação social da profissão; da revisão constante dos significados sociais da profissão; da revisão das tradições. Mas também da reafirmação de práticas consagradas culturalmente e que permanecem significativas [...]. Constrói-se também pelo significado que cada professor, enquanto ator e autor, confere à atividade docente no seu cotidiano a partir de seus valores, de seu modo de situar-se no mundo, de sua história de vida, de suas representações, de seus saberes, de suas angústias e anseios, do sentido que tem a sua vida o ser professor. Assim como a partir da sua relação com os outros professores, nas escolas, nos sindicatos e em outros agrupamentos.

Para Pimenta (2002) a educação é um processo de humanização, é um processo pelo qual os seres humanos são inseridos na sociedade. O indivíduo ao iniciar sua formação já possui conhecimento empírico que representam os valores e hábitos construídos no dia a dia, e cabe a cada um desses indivíduos envolvidos nos processos de ensino-aprendizagem agregar os saberes sistematizados cientificamente, sendo estes mais elaborados e que construímos na escola e/ou na Universidade.

Neste mundo moderno cada vez mais se faz necessário investir em uma formação de qualidade, e em professores que articulam suas experiências práticas sendo profissionais e fazendo a mediação dos conhecimentos no processo de aprendizagem dos seus alunos, para que não venhamos a ter o fracasso e desigualdades escolares (PIMENTA, 2002).

Sendo assim, essas pesquisas vêm esclarecer na visão da autora que a formação docente na prática deve ser vista como processo de investigação articulado entre teoria e prática. Entretanto, para a autora, "teoria e prática são indissociáveis como práxis". (PIMENTA, 2006, p. 93). O professor é considerado o elo no processo educativo formal, pois cabe a ele ser o pesquisador e mediador da aprendizagem, mas ele só fará a diferença se assumir a responsabilidade pelo seu papel, que é o de educador, levando em conta suas responsabilidades e compreendendo o seu trabalho.

Através das pesquisas de Maurice Tardif (2002) é possível perceber que este autor discute e aborda questões voltadas à profissão docente e à formação de professores com relação à carreira profissional e a aprendizagem do trabalho docente.

Segundo Tardif (2002), a formação dos professores está historicamente ligada à profissionalização do ensino e as reformas escolares. Nos últimos dez anos vêm se tendo uma reformulação do ensino, uma das mais importantes que aconteceu foi que o profissional da educação surgiu através da interferência do Estado, que substituiu a Igreja pela escola.

Saberes Pedagógicos, Criciúma, v. 1, n², julho/dezembro 2017.- Curso de Pedagogia- UNESC 
Revista do Curso de Graduação de Pedagogia - Unesc

Com a trajetória educacional o professor não é mais o detentor do conhecimento, mas torna os momentos de aprendizagem possíveis, deixando que seus alunos possam expor suas ideias e conhecimentos de sensos comuns e assim, juntos pesquisarem adentrando ao conhecimento científico.

Segundo Tardif (2002, p. 23):

[...] expressa a vontade de encontrar, nos cursos de formação de professores, uma nova articulação e um novo equilíbrio entre os conhecimentos produzidos pelas Universidades a respeito do ensino e os saberes desenvolvidos pelos professores $\mathrm{em}$ suas práticas cotidianas [...].

Assim, a formação dos professores deve se conectar entre teoria e prática, contudo, esta formação deve oferecer aos seus acadêmicos materiais de embasamento teórico para que fortaleça a mediação na prática, contribuindo assim para a aproximação entre o sujeito ensinante e o sujeito ensinado. O professor estará mediando o ensino-aprendizagem, pois ele é o indivíduo que ensina o conhecimento técnico e ao mesmo tempo está em constante aprendizado quando se trata das relações entre os envolvidos no processo de aprendizagem. Defende-se a articulação entre teoria e prática, pois compreende-se como momento enriquecedor para a sua atuação como professor, buscando analisar e refletir sobre a sua ação dentro da sala de aula.

É possível compreender que a teoria e a prática são processos ligados um ao outro, pois uma dá suporte à outra, sendo que a teoria oferece instrumentos, didáticas, autores, documentos que auxiliam no planejamento em sala de aula na elaboração de planos e projetos para serem executados para que se torne possível alcançar os objetivos propostos no processo de aprendizagem. São importantes também as trocas de experiência entre os indivíduos envolvidos no processo de ensino, para que gere transformações e conhecimento, é preciso que o professor trabalhe em uma mão de via dupla entre a teoria e a prática. De acordo com Ghedin; Almeida e Leite (2008, p. 15), “[...] separar essas duas dimensões da existência humana é o maior descaminho da ação profissional do professor”.

Tardif (2002, p. 44) afirma que “[...] a formação dos professores perde, simultaneamente, sua característica de formação geral para se transformar em formação 
Revista do Curso de Graduação de Pedagogia - Unesc

profissional especializada". Contudo, através das mudanças da sociedade houve momentos de melhoria para a formação dos professores.

Segundo Tardif (2002), primeiro a formação girava em torno dos saberes disciplinares, ou seja, são saberes que correspondem aos diversos campos do conhecimento, sob forma de disciplinas. Em seguida a formação girava sobre os saberes curriculares, neste o professor deveria se apropriar dos saberes, sob a forma de programas escolares, os professores deveriam aprender a aplicar conteúdos, objetivos, métodos. Por fim na formação finalmente teremos os saberes experienciais ou práticos, em que os professores no exercício das suas funções e na prática da sua profissão incorporam as experiências individuais e coletivas.

Para buscar uma profissionalização de professor é necessária a busca por uma boa formação, é importante que o professor saiba seu conteúdo, sua matéria, seus programas, além de possuir conhecimentos gerais e conseguir fazer articulações entre a sua prática e a do grupo em qual trabalha, sendo assim integrando outros conhecimentos em sua prática educacional (TARDIF, 2002). Ou seja, conforme vamos adquirindo experiências profissionais, vamos constituindo-nos e nos formando como sujeitos autônomos, críticos, reflexivos, e assim nos tornaremos professores pesquisadores de nossa própria prática pedagógica.

As ideias dos autores utilizados para a realização desta seção têm conexões em seus estudos acerca da formação de professores. Nóvoa (1992; 2009) trabalha essa temática afirmando que a formação anda em constantes transformações, que cabe ao professor estar sempre se questionando e, assim, tornar-se um sujeito reflexivo de suas próprias práticas educativas.

Pimenta (2005) nos revela a formação e a profissionalização docente como um processo entre a teoria e a prática, também levando o professor a se tornar um pesquisador para a transformação da prática e a aplicação de novos conhecimentos. Tardif (2002) é um bom entendedor no que diz respeito à valorização do papel do professor como sujeito motivador da aprendizagem. Ele também faz muitas críticas às metodologias angloamericanas, europeias tecnicistas, o que podemos entender que vai de acordo com os outros dois autores apresentados de que o professor deve buscar envolvimento com a sua prática pedagógica.

Saberes Pedagógicos, Criciúma, v. 1, n², julho/dezembro 2017.- Curso de Pedagogia- UNESC 
Revista do Curso de Graduação de Pedagogia - Unesc

Entretanto, torna-se necessária a preparação dos professores com formações continuadas e com as trocas de experiência dentro da profissão e com as colegas, para que consigamos elencar nossas experiências individuais na prática com nossas experiências profissionais e do professorado. Compreender a formação docente coincide com a reflexão de que ser professor é ser um profissional da educação que trabalha com pessoas. Essa percepção induz este profissional de educação a um processo permanente de formação, na busca constante do conhecimento por meio dos processos pedagógicos que darão suporte a sua prática.

Na próxima seção são apresentadas as diretrizes que regulamentam o Estágio Supervisionado Obrigatório do curso de licenciatura em Pedagogia da UNESC.

\section{DIRETRIZES QUE REGULAMENTAM O ESTÁGIO SUPERVISIONADO OBRIGATÓRIO}

Nesta seção serão apresentadas as diretrizes e documentos que regularizam os estágios supervisionados obrigatórios, tais como Resolução nº.13/2009/UNA HCE e CNE/CP $\mathrm{n}^{\mathrm{o}} .15$ de maio de 2006.

\subsection{Regulamento de estágio do curso de licenciatura da UNESC}

O documento que regulamenta tanto o estágio supervisionado obrigatório quanto o não obrigatório da UNESC é a Resolução n.13/2009/UNA HCE, e que entrou em vigor no segundo semestre de 2009 e continua valendo até o presente momento.

A organização dos estágios curriculares obrigatórios do curso de Pedagogia obedece às competências estabelecidas pelas legislações vigentes e especialmente pelo Regulamento Geral de Estágios dos Cursos de Graduação da UNESC (UNESC, 2009). Os estágios ocorrem na docência da educação infantil, anos iniciais, educação de jovens e adultos, magistério e no campo da gestão escolar.

De acordo com UNESC (2009), apresentamos aqui a sistemática dos estágios supervisionados obrigatórios. Dentre todos os estágios acima citados, alguns são exigidos somente observação, já outros, observação e posteriormente a atuação. Os acadêmicos têm o

Saberes Pedagógicos, Criciúma, v. 1, n², julho/dezembro 2017.- Curso de Pedagogia- UNESC 
Revista do Curso de Graduação de Pedagogia - Unesc

livre arbítrio para a escolha da instituição de ensino para realizar seus estágios, de acordo com a fase que estiver cursando. Escolhida a instituição de ensino o acadêmico deverá informar os dados desta para a secretaria do curso para que seja possível gerar os termos de compromissos que serão três vias, uma para a instituição, uma para o acadêmico e outra que será entregue junto com as fichas de controle dos dias e horários em que ocorreram o estágio, sendo que devem ser assinadas e carimbadas pela instituição escolhida.

A UNESC concede um professor responsável que orienta até 15 alunos, sendo de sua competência orientar na elaboração, execução do projeto ou plano de aula e acompanhamento do acadêmico. Os estagiários também contam com um supervisor de campo que fica responsável por prestar informações para o professor responsável, assim como assinar as fichas de presença e avaliação do estagiário. Após a conclusão desta etapa é realizado um relatório e uma socialização de estágio, cada um correspondente em sua fase com nomenclatura SEMIC I, II, III, e após e realizada uma prova e entregue toda a documentação para as professoras responsáveis.

\title{
3.2 Conselho Nacional de Educação Conselho Pleno Resolução CNE/CP Nº 1, de 15 de maio de 2006
}

As Diretrizes Curriculares Nacionais para o curso de Pedagogia licenciatura alicerça a vida de um pedagogo, pois nelas são encontradas informações que dão suporte ao professor e colaboram para com sua prática tangível a respeito da identidade do curso e da sua finalidade profissionalizante.

Diante disso, no artigo $4^{\circ}$ :

\begin{abstract}
O curso de Licenciatura em Pedagogia destina-se à formação de professores para exercer funções de magistério na Educação Infantil e nos anos iniciais do Ensino Fundamental, nos cursos de Ensino Médio, na modalidade Normal, de Educação Profissional na área de serviços e apoio escolar e em outras áreas nas quais sejam previstos conhecimentos pedagógicos (BRASIL, 2006).
\end{abstract}

Sendo assim, DCN/Pedagogia apresenta um conjunto de normas e características organizadas para o docente quanto a sua área de atuação. O pedagogo trabalha com diversos conhecimentos e é influenciado por várias áreas.

A resolução enfatiza as relações entre a teoria e prática, em seu Art. $3^{\circ}$ :

Saberes Pedagógicos, Criciúma, v. 1, n² , julho/dezembro 2017.- Curso de Pedagogia- UNESC 
[...] trabalhará com um repertório de informações e habilidades composto por pluralidade de conhecimentos teóricos e práticos, cuja consolidação será proporcionada no exercício da profissão, fundamentando-se em princípios de interdisciplinaridade, contextualização, democratização, pertinência e relevância social, ética e sensibilidade afetiva e estética (BRASIL, 2006).

Sendo assim, leva o pedagogo a ter conhecimento organizacional e sistemático da escola em que está inserido para que através da educação sejam incentivados cidadãos críticos e reflexivos perante a sociedade. O pedagogo ainda deve ter uma postura investigativa, interativa e positiva, como apresentado no Art.5 e inciso IX:

Identificar problemas socioculturais e educacionais com postura investigativa, interativa e propositiva em face de realidades complexas, com vistas a contribuir para a superação de exclusões sociais, étnicos-raciais, econômicas, culturais, religiosas, políticas e outras (BRASIL, 2006).

Segundo a diretriz em questão, o pedagogo tendo essas posturas irá pesquisar sua classe, sua escola, tentará fazer parte da vida de seus alunos, colegas e colaboradores, para que possam fazer seus trabalhos em conjunto e de maneira intencional no entorno da comunidade escolar.

\section{ESTÁGIO SUPERVISIONADO OBRIGATÓRIO}

O estágio supervisionado obrigatório tem a finalidade de apresentar ao docente em formação uma aproximação com o ambiente de trabalho e com a realidade na qual ele irá se inserir no mercado de trabalho. Assim sendo, este é momento de se colocar em prática as teorias estudadas. Segundo Pimenta e Lima (2004, p. 33), “o estágio sempre foi identificado como a parte prática dos cursos de formação de profissionais, em contraposição à teoria”.

Assim, o estágio no curso de licenciatura em Pedagogia pode-se denominar como a experiência mais prática do curso com relação às outras disciplinas do currículo. De acordo com Moraes (2012, p. 20), “o estágio é o momento de sintetizar a aproximação com o que chamamos de práxis, processo em que a teoria e prática dialogam em torno de uma ação crítica e reflexiva". 
Revista do Curso de Graduação de Pedagogia - Unesc

Não se deve pensar no estágio supervisionado obrigatório como uma tarefa burocrática apenas a ser cumprida, para a obtenção do diploma de conclusão de curso, mas sim assumi-la como uma função prática do ensino criando situações de aprendizagem dinâmica e assumindo perante a sala de aula uma postura profissional adequada.

Assim, ao elaborar os projetos de intervenção pedagógica o docente em formação no estágio supervisionado obrigatório poderá aplicá-los, assumindo, pela primeira vez, a postura de professor. A aplicação dos projetos ou planos de aula, na modalidade e a regência no estágio supervisionado obrigatório o docente em formação não cumpre simplesmente uma exigência do curso, mas contribui para uma aula diversificada, além de, posteriormente, olhar para as suas experiências e delas constituir sua identidade. É a partir dessas primeiras sensações que ele poderá habituar-se pela profissão e apresentar alternativas de melhorias em sala de aula (PIMENTA, 2005).

O estágio supervisionado obrigatório inicia-se na formação no exercício da atividade docente, por isso sua forma de organização e as vivências desenvolvidas nele são fundamentais. Ele acontece por meio da observação, da participação e da regência, o licenciando poderá refletir sobre e vislumbrar futuras ações pedagógicas.

Segundo Lima (2012, p. 63), "o período de observação tem como objetivo a coleta e organização do registro de dados", ou seja, o sistema organizacional da escola, como acontece à rotina dos alunos e a postura do professor regente com quem irão atuar.

Em relação à atuação Pimenta (2005, p. 153) apresenta que "as atividades de regência/intervenção são muito valorizadas [...] porque nelas têm a possibilidade de 'praticar' o manejo da classe, exercitar como ensinar, seja porque têm a visão e o controle do processo todo (planejamento, execução, avaliação)".

Entretanto, sua formação tornar-se-á mais significativa quando essas experiências forem socializadas em sua sala de aula com seus colegas, produzindo discussão, possibilitando uma reflexão crítica, construindo a sua identidade profissional. De acordo com Lima (2012, p. 45), “o estágio na formação docente deve levar em conta que os profissionais da educação se movem nas complexas relações humanas e sociais, nos regulamentos e tradições que acontecem na escola”. 
Revista do Curso de Graduação de Pedagogia - Unesc

O estágio supervisionado obrigatório poderá ser um agente contribuidor na formação do professor, caracterizando-se como objeto de estudo e reflexão. Ao estagiar, o futuro docente em formação passa a enxergar a educação com outro olhar, procurando entender a realidade da escola e o comportamento dos alunos, dos professores e dos profissionais que a compõem. Com isso faz uma nova leitura do ambiente (escola, sala de aula, comunidade), procurando meios para intervir positivamente.

Freire (2001) leva a refletir nos estágios pedagógicos como aquisição dos saberes relacionado ao como ensinar, como agir profissionalmente e possibilita a transição do pensamento acadêmico para o pensamento pedagógico. Os estágios supervisionados obrigatórios como prática para a formação docente são o elo articulador entre teoria e prática. Logo, algumas teorias serão revisadas antes da sua aplicação, para isso busca-se uma boa formação, pois se lida com o conhecimento do outro, sendo assim este primeiro contato do estagiário servirá para que se percebam os erros e acertos dentro da sala de aula.

\section{METODOLOGIA, APRESENTAÇÃO E ANÁLISE DE DADOS}

Esta pesquisa é pautada em uma abordagem qualitativa de cunho descritivo e exploratório que nos permitiu buscar informações nas literaturas. Pesquisa descritiva e exploratória porque foi desenvolvido um questionário com perguntas (PINHEIRO, 2010). O estudo está vinculado à linha de pesquisa Formação dos Profissionais da Educação.

O objetivo desta pesquisa é saber "qual a contribuição do estágio supervisionado obrigatório para a formação docente na perspectiva do licenciando no curso de Pedagogia da UNESC", tendo em vista que este se faz necessário para que o docente em formação consiga concluir esta etapa da graduação.

Os sujeitos que participaram desta pesquisa foram os acadêmicos que estavam cursando a $8^{a}$ fase do curso de licenciatura em Pedagogia da UNESC no ano de 2016/1, no município de Criciúma-SC, com a aplicação de um questionário com 13 perguntas. Os sujeitos pesquisados têm como entidade formadora a universidade UNESC e o curso de licenciatura Pedagogia. 
Revista do Curso de Graduação de Pedagogia - Unesc

Foram entregues 28 questionários para os acadêmicos que estavam cursando a $8^{\mathrm{a}}$ fase do curso de Pedagogia licenciatura, mas, retornaram apenas 15 questionários respondidos. Esses foram os sujeitos que se disponibilizaram a participar da pesquisa, a escolha se deu em virtude de já terem concluído todos os estágios supervisionados obrigatórios e pela aceitação deles em participar desta pesquisa.

Para a análise deste trabalho dividimos as perguntas por categorias, sendo assim serão encontradas quatro categorias: Sobre os sujeitos da pesquisa; As expectativas e as experiências do estágio; Perante a organização do estágio; Articulação entre teoria e prática. Para o resguardo das informações identificaremos os sujeitos por letras e números, AC1, AC2, AC3, e assim sucessivamente.

\subsection{Sobre os sujeitos da pesquisa}

Optamos por trabalhar com os acadêmicos que em 2016/1 já haviam cursado todas as disciplinas de estágio supervisionado obrigatório, e estavam na última fase do curso de licenciatura em Pedagogia da UNESC. Para conhecermos os sujeitos pesquisados elaboramos os quadros 1 e 2 abaixo, para visualização das informações gerais sobre o sexo dos participantes e sobre qual a modalidade que mais contribuiu na sua formação profissional.

Quadro 1 - Número de sujeitos pesquisados por sexo

\begin{tabular}{|c|c|c|}
\hline Número total & Masculinos & Femininos \\
\hline 15 & 2 & 13 \\
\hline
\end{tabular}

Fonte: Dados da autora, 2016.

Quadro 2 - Modalidades de Estágio que mais contribuíram para sua formação profissional

\begin{tabular}{|l|c|c|c|c|c|}
\hline & Anos Iniciais & EJA & Ed. Infantil & Gestão Escolar & Magistério \\
\hline Sujeitos & 6 & 3 & 7 & 2 & 1 \\
\hline
\end{tabular}

Fonte: Dados da autora, 2016.

No Quadro 1 é possível perceber que a procura pelo curso de Pedagogia ainda é caracterizada por um número maior de mulheres. O Quadro 2 acima apresenta a escolha e o interesse dos pesquisados na modalidade de ensino que mais contribuiu para a sua formação. Dos pesquisados, sete destacam a escolha pela modalidade de Educação Infantil que

Saberes Pedagógicos, Criciúma, v. 1, n² , julho/dezembro 2017.- Curso de Pedagogia- UNESC 


\section{SABERES PEDAGÓGICOS}

Revista do Curso de Graduação de Pedagogia - Unesc

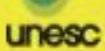

Unethoe Aridan Acadanica

do Humaridadec.

contribuiu para sua formação profissional, sendo que historicamente essa modalidade era voltada ao assistencialismo ao cuidado com as crianças, e não em compreender a criança como um sujeito histórico.

Esses dados confirmam-se quando Ferreira e Carvalho (2006) afirmam que o número de mulheres que procuram cursos de formação de professores, principalmente nos níveis da Educação Infantil e anos iniciais do Ensino Fundamental, é maior do que o número de homens.

\subsection{As expectativas e as experiências do estágio}

Questionados se o estágio supervisionado obrigatório contribuiu para definição da área de atuação, 12 dos pesquisados afirmaram que sim, um respondeu que não contribuiu pela falta de experiência em sala de aula, enquanto dois disseram ter contribuído, mas não definido a sua área de atuação.

Segundo Moraes (2012, p. 14), “[...] o estágio curricular enquanto momento privilegiado de formação do futuro profissional, independentemente da área [...]" que ele venha escolher pra trabalhar, este é a ponte em que o docente em formação tem para experimentar e contribuir pra definição da sua área de atuação e com a sua prática pedagógica.

Com relação à expectativa do estágio supervisionado obrigatório os sujeitos pesquisados deveriam se manifestar numa ordem prioritária, $1^{\text {a a }} 4^{\text {a }}$ conforme Quadro 3 a seguir:

Quadro 3 - Indicador de expectativa em relação ao estágio supervisionado obrigatório

\begin{tabular}{|l|c|c|c|c|}
\hline & $1^{\circ}$ lugar & $2^{\mathbf{o}}$ lugar & $3^{\circ}$ lugar & $4^{\circ}$ lugar \\
\hline Experiência profissional & 2 & 1 & 6 & 4 \\
\hline Como cumprimento da disciplina apenas para ser avaliado & 2 & 1 & 2 & 7 \\
\hline Aproximação entre teoria e prática & 11 & 3 & & \\
\hline Contribuiu para a sua formação e profissional & 1 & 7 & 3 & 1 \\
\hline
\end{tabular}

Fonte: Dados da autora, 2016.

Sendo assim, a leitura deste quadro se faz da seguinte maneira: em $1^{\mathrm{a}}$ lugar

Saberes Pedagógicos, Criciúma, v. 1, n²2, julho/dezembro 2017.- Curso de Pedagogia- UNESC 
Aproximação entre teoria e prática, vai ao encontro do que Ghedin; Almeida e Leite (2008, p. 15) afirmam, que "não há prática sem teoria e nem teoria sem prática, [...]”. É perceptível que no estágio supervisionado obrigatório é possível fazer a articulação da teoria e prática dentro da sala de aula e no momento em que se está em contato com os alunos.

Em $2^{\circ}$ lugar Contribuiu para a sua formação profissional e $3^{\circ}$ lugar Experiência profissional vão ao encontro do que Nóvoa (1992, p. 16) afirma, que "a formação de professores pode estimular o desenvolvimento profissional dos professores". Entretanto, se o estágio supervisionado for aplicado com responsabilidade perante as situações de aprendizagem elevará o próprio desenvolvimento pessoal.

Em $4^{\circ}$ lugar, Como cumprimento da disciplina apenas para ser avaliado. Através da pesquisa foi possível observar que os pesquisados estão empenhados em fazer a diferença e entendem que o espaço do estágio é mais do que apenas colocar as teorias em prática, é uma “experiência enriquecedora, é uma oportunidade para o estagiário em formação [...]” (LIMA, 2012, p. 132). Ou seja, conhecer a profissão, antes mesmo de se tornar professor.

No que se refere às dificuldades encontradas no estágio supervisionado obrigatório, entre os pesquisados, apresentamos quatro dificuldades que nos chamaram atenção por se tratar da burocracia e do pouco tempo de observação e elaboração do projeto.

AC14 - Encontrei algumas dificuldades principalmente quando era pra procurar escola para fazer o estágio, isso foi algo interessante, além de ter que fazer o estágio obrigatório pensar no que ensinar, ter que ir atrás de escola é difícil. Penso que deveria ter alguém, algum setor que ajudasse nessa tarefa, principalmente para quem não tem contato com as escolas.

AC2 - Sim, a maior dificuldade que enfrentei foi a ansiedade, mas também gostaria de ter mais tempo para elaboração do projeto, pois quando observamos a professora passa um tema ou conteúdos ela já supõe uma data para retorno para atuação, e com isso corremos para planejar e ainda temos que passar pela surpresa do estágio e a professora da sala.

AC5 - Sim, a dificuldade maior estava em elaborar um projeto para uma turma já em andamento sem conhecimento dos alunos, pois o tempo de observação não é o suficiente para conhecermos a turma.

AC7 - Sim, por vezes o número de dias direcionado à observação me pareceu insuficiente para conhecer as limitações ou aptidões dos alunos. Isso mesmo quando havia conversa com a titular da sala, pois só desta forma se conhecia realmente a turma.

No decorrer dos estágios algumas dificuldades são encontradas e cabe ao docente superá-las, entretanto, como afirma Pimenta (2005, p. 150), “o estágio deverá servir como Saberes Pedagógicos, Criciúma, v. 1, n², julho/dezembro 2017.- Curso de Pedagogia- UNESC 
fonte de reflexão sobre os aspectos teórico-práticos do processo de ensino e aprendizagem”.

Ainda nesta categoria os sujeitos pesquisados deveriam avaliar as disciplinas de estágio supervisionado obrigatório em termos de orientação e acompanhamento. Em unanimidade responderam que foi "ótimo", que sempre que foi preciso elas (Professoras Responsáveis) estavam dispostas a orientar e auxiliar até mesmo fora dos horários de aula. Portanto, destacamos a escrita de dois participantes:

\begin{abstract}
AC1: Orientação é algo muito importante para que o acadêmico se sinta seguro, e tenha clareza no que vai apresentar na atuação. Acompanhamento deixa o aluno aflito, porém é necessário.

AC14: Quanto às disciplinas de estágio obrigatório supervisionado tiveram algumas dificuldades, o que é interessante para o aluno também, fazer o seu questionamento para aprender e tentar procurar uma solução para os problemas. A educação precisa fazer com que as pessoas deixem de ser comandadas para comandar. As pessoas precisam pensar, exercitar o pensamento, não ter tudo pronto.
\end{abstract}

A profissão de um professor se constrói dentro de quatro pilares como base: os saberes da formação profissional, os saberes disciplinares, os saberes curriculares e os saberes experienciais, que são construídos no decorrer do seu cotidiano (TARDIF, 2002). As respostas sobre a orientação e acompanhamento se aproximam de nosso referencial teórico quando Pimenta e Lima (2004, p. 127) afirmam que "a função do professor orientador do estágio será a luz da teoria, refletir com seus alunos sobre as experiências que já trazem e projetar um novo conhecimento que ressignifique as suas práticas, [...]”. Sendo assim, tornarem-se professores reflexivos e pesquisadores da sua prática como docente.

\title{
4.3 Perante a organização do estágio
}

Dentro desta categoria a primeira questão abordada foi qual era a importância da observação e da atuação do estágio supervisionado obrigatório do curso de Pedagogia. Os sujeitos envolvidos sabem o real valor da atuação e da observação, pois encontramos em suas respostas:

AC3 - Observação para conhecer a estrutura da escola, o funcionamento, a rotina, os profissionais envolvidos e as crianças para fazer o projeto e poder atuar com eficácia. Atuação a prática é fundamental serve como experiência.

Saberes Pedagógicos, Criciúma, v. 1, n², julho/dezembro 2017.- Curso de Pedagogia- UNESC 
AC6 - Primeiramente são imprescindíveis para nossa formação. Através da observação podemos conhecer a turma e planejar de que forma iremos trabalhar com eles. Posteriormente, através da atuação, podemos refletir sobre a relação teoria e prática, além de "aprender a ensinar", pois cada turma é uma realidade diferente.

AC9 - Eu achei importante a observação porque é o primeiro contato com os alunos e professores, e a partir da observação nós nos sentimos mais a vontade na hora da atuação.

AC10 - Os estágios são muito importantes para nossa formação. A observação nos permite conhecer a turma e familiarizar-se com os alunos. E a prática nos permite fazer relações com a teoria aprendida na universidade e de ser professora de fato.

AC13 - Torna-se importante no processo de formação docente pelo fato de que diagnostica a realidade dos alunos/as para elaborar projetos referentes à necessidade da classe.

Entretanto, essas respostas vão ao encontro de Lima (2012), que traz o estágio de observação como oportunidade de pesquisa em que o estagiário busca entender o funcionamento da escola em que irá atuar. Já a atuação Pimenta (2006) retrata como momento de executar o seu planejamento pedagógico com autonomia.

Os sujeitos pesquisados deveriam responder quais eram as contribuições dos estágios supervisionados obrigatórios para a sua formação.

AC2 - Foram muitas, o estágio proporciona o estudo aprofundado na busca de teoria que embasam a justificativa como também é um exercício de planejamento, organização dos planos de aula. E a maior contribuição é estar no ambiente escolar e poder atuar com os alunos vivenciando o cotidiano escolar.

AC6 - Aprendi sobre como é atuar em cada turma. Aprendi sobre como são os sujeitos da aprendizagem. Por exemplo, não se ensina os alunos da EJA da mesma forma que os alunos da E.F., apesar dos conteúdos serem os mesmos. Além disso, agora eu sei que posso atuar em qualquer uma dessas áreas, pois tive preparação e formação para isso.

O que se respalda quando levantamos a questão de Freire (2001, p. 19):

Os estágios pedagógicos permitem aos estagiários a aquisição de saberes, relacionados com o como ensinar e o como agir profissionalmente e também consciencialização das mudanças que neles vão realizando, possibilitando a compreensão do sentido da mudança, o que pode facilitar a transição do pensamento acadêmico para o pensamento pedagógico.

Entretanto, também encontramos respostas como:

AC14 - As contribuições do estágio supervisionado para a minha formação acadêmica foram para ter o olhar para educação. Esse contato na escola faz com que

Saberes Pedagógicos, Criciúma, v. 1, n², julho/dezembro 2017.- Curso de Pedagogia- UNESC 
percebemos a realidade de um sistema educacional precária e que faz com que nós não tenhamos opiniões e vontades próprias, tudo ou quase tudo é um meio para nos manipular.

Contudo, deve-se refletir com Nóvoa (2009, p. 7), quando ele descreve que temos que "criar hábitos de reflexão e autorreflexão". Não basta apenas observar que é precário o sistema educacional, mas em compreender o que posso fazer para que não caia no tradicionalismo escolar.

Questionamos os pesquisados se eles levaram para suas atuações intervenções inovadoras e transformadoras, pois vimos ao longo do curso que devemos mediar o conhecimento atribuído através de novas didáticas estudadas. Com isso apresentamos:

\begin{abstract}
AC4 - Sim, procurei levar trabalhos diferenciados para sair da rotina que eles estavam acostumados. Na educação infantil e séries iniciais sim trabalhando com o lúdico e na EJA procuramos conhecer bem o grupo para escolhermos as atividades que os interessassem, pois eles já estavam cansados de receber estagiárias.

AC5 - Sim, porque eu trabalhei com atividades que envolviam os alunos a todo o momento, sendo que uma professora chegou a dizer que não daria certo porque eles não eram acostumados a fazer daquela forma "participativa e inovadora".

AC6 - Sim, em alguns aspectos. O tempo de cada estágio é pouco para se afirmar que a atuação foi transformadora ou inovadora. No entanto, busquei trabalhar de forma que as crianças/alunos interagissem e se interessam pela aula, busquei dar as aulas de forma dinâmica, trazendo brincadeiras, jogos... Acho que esse foi o diferencial.
\end{abstract}

Sendo assim, “[...] análise das situações vivenciadas e observadas permite o desenvolvimento de uma compreensão mais ampla das teorias estudadas, [...] para intervir na realidade" (PIMENTA; LIMA, 2004, p. 204). Observa-se que os sujeitos pesquisados buscaram primeiro entender através das observações as modalidades e turmas em que atuariam para, assim, adotarem procedimentos de acordo com cada realidade.

Por fim questionamos se a escola/professor titular lhe tratou como um profissional docente em formação, dos 15 sujeitos pesquisados 14 afirmou terem sido "bem acolhidos na escola escolhida para observar e atuar". De acordo com Lima (2012 p. 68) “a passagem do estagiário pela escola-campo é um espaço de autoformação [...], que compõe o ser e estar na profissão".

Portanto, AC1 responde "Mal, pois não valorizaram a estagiária". Em nossas buscas por fundamentação teórica dialogamos com Lima (2012, p. 75), que traz que a Saberes Pedagógicos, Criciúma, v. 1, n² , julho/dezembro 2017.- Curso de Pedagogia- UNESC 
Revista do Curso de Graduação de Pedagogia - Unesc

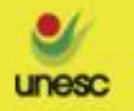

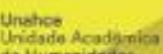

unesc

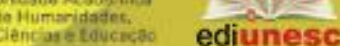

observação da rotina não é algo sem fruto, pois "a conversa estabelecida entre o professor da escola-campo e o estagiário é muito mais do que uma atividade rotineira de operacionalidade docente". Nesta resposta é possível sentir o distanciamento entre o professor titular/ escola campo em perceber que o estagiário e um profissional em formação.

Isso nos respalda em Lima (2012, p. 75): “É a possibilidade de aprendizagem, de trocas de experiência, crescimento mútuo com os percursos, com significações dadas à profissão e com as práticas pedagógicas, que foram surgindo no cotidiano e nas relações com a escola, sua comunidade e seu contexto". Ou seja, esses professores que receberam os estagiários entendem o estágio como uma prática da profissão por já terem passado por esta etapa de docente em formação e a contribuição que o estágio oferece para a formação profissional.

\subsection{Articulação entre teoria e prática}

No decorrer deste artigo falamos tanto em pôr em prática a teoria estudada que pedimos para os sujeitos pesquisados que nos dessem uma nota de 0 a 5 se o estágio supervisionado obrigatório lhe ofereceu embasamento teórico dentro do curso de Pedagogia da UNESC (lembrando que o 0 era considerado como não possuindo embasamento teórico e 5 como possuindo todo o embasamento suficiente). Obtivemos a nota 4 de nove participantes e nota 5 de seis participantes. O que nos fez compreender que o embasamento teórico é construído ao longo do decorrer da prática profissional, e com isso vem nos apresentando o estágio como o momento de colocar as teorias estudadas em prática (LIMA, 2012).

Também questionamos se foi possível fazer a articulação da teoria estudada em sala na execução de sua prática. De acordo com as respostas podemos afirmar que para os sujeitos pesquisados a teoria entende-se como as disciplinas, os seminários, as discussões realizadas em sala sempre um semestre antes da atuação e durante o processo de formação, já a prática é articular essas teorias dentro de seus planos de aula, é a vivência dentro da realidade escolar, é o convívio entre os colaboradores, professores e alunos dentro do ambiente escolar. Sendo assim, destaca-se a escrita dos seguintes pesquisados:

Saberes Pedagógicos, Criciúma, v. 1, n², julho/dezembro 2017.- Curso de Pedagogia- UNESC 
AC4 - Todo o trabalho prático deve ter um objetivo, uma finalidade e não tem como chegar a esse objetivo sem ser baseado em uma teoria. A teoria nos faz compreender como acontece a aprendizagem e a melhor maneira de alcança-la.

AC6 - Os estágios sempre ocorreram em semestres posteriores às disciplinas que tratavam especialmente de cada fase. Assim, antes de ir para cada estágio, já havíamos trabalhado sobre os conteúdos que se ensina na série/ano e sobre metodologias para ensinar de forma criativa e significativa. Nesse sentido, quando fomos atuar, já havíamos construído conhecimentos teóricos para embasar nossa prática docente. Assim pudemos perceber a relação existente entre a teoria e a prática, bem como perceber os problemas de articular a teoria com a prática, pois cada realidade é diferente e vai depender muito de como o docente trabalha, no sentido de "teorizar a sua prática e praticar a teoria".

AC10 - Foi ótima, pois as disciplinas que tinham nos semestres anteriores ofereceram subsídios de muitas maneiras nesta relação.

AC13 - Foi possível articular através das vivencias e experiências obtidas tanto na formação acadêmica que deu embasamento teórico, quanto na vivência da realidade em sala de aula positiva e negativa.

AC14 - A articulação acontece quando internalizamos o conceito e conseguimos lecionar em sala de aula. Por exemplo, se estamos lecionando sobre português e em determinado momento da aula conseguimos articular com a matemática, significa que dominamos teoria e prática, mesmo que às vezes isso não acontece.

Contudo, para Pimenta (2006, p. 58), “[...] o acesso ao conhecimento explícito da dominação não é automático; requer a mediação dos professores que, na prática educativa, têm como objetivo de seu trabalho tornar viva e explícita a finalidade sócio-política da educação escolar”. Sendo assim, de acordo com as respostas citadas foi possível verificar junto aos pesquisados que a teoria e a prática são processos indissociáveis.

Para finalizar a pesquisa foi solicitado que escrevessem o nome de autores que sustentaram seus planos e projetos de atuação. No entanto, os sujeitos da pesquisa dividiram esta questão entre teóricos e documentos, contudo apresentamos os que foram citados mais vezes e obtivemos o seguinte resultado: Teóricos citados, Vygotsky (10), Piaget (7) e Soares (5). Documentos citados, PCNs (7), RCNEIs (4) e PCSC (2). Diante das respostas da pesquisa, obtivemos dados importantes perante a formação docente através dos estágios supervisionados obrigatórios. Podemos afirmar que este é o momento de se confirmar como profissional da educação, de integração entre os conhecimentos teóricos na prática de dar oportunidade ao docente oferecendo tempo para refletir sobre sua prática.

\section{CONCLUSÃO}

Realizar esta pesquisa visando analisar a contribuição do estágio supervisionado Saberes Pedagógicos, Criciúma, v. 1, n², julho/dezembro 2017.- Curso de Pedagogia- UNESC 
Revista do Curso de Graduação de Pedagogia - Unesc

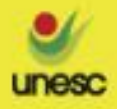

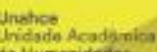

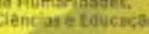

obrigatório para a formação docente na perspectiva do licenciando do curso de licenciatura em Pedagogia da UNESC demanda compreendermos que todos os estágios têm um impacto perante a formação acadêmica e profissional.

Entretanto, ao longo do caminho percorrido nesta pesquisa foi possível identificar estudos e pesquisas que tratam da formação de professores como atividade formativa tanto para a vida pessoal como para a vida profissional. O estágio supervisionado obrigatório do curso de Pedagogia é uma atividade formativa na medida em que se relaciona teoria e prática.

Descrever as percepções dos licenciados em Pedagogia sobre o estágio supervisionado obrigatório indica que esta preparação é importante por se conseguir articular a teoria com a prática e conseguir vivenciar as modalidades de atuação. Contudo, encontramos também percepções que indicam a necessidade de ampliação do tempo de observação em sala de aula com vista à construção de um planejamento mais próximo à realidade escolar, por existir sujeitos distanciados deste ambiente escolar, por terem escolhido essa área de graduação, mas no momento dos estágios estarem trabalhando profissionalmente em outra área.

O estágio supervisionado obrigatório é um dos momentos privilegiados de articulação entre a teoria e a prática, reflexão da sua ação pedagógica. É a possibilidade para experimentar todas as áreas de atuação do pedagogo, reconhecer o ambiente escolar, atuar e vivenciar o cotidiano e a realidade da escola e preparação para enfrentar o mercado de trabalho.

O estágio realmente é de suma importância para a compreensão da realidade escolar e faz com que o docente em formação perceba que ser professor é ser um profissional que se encontra em processo de formação permanente, e assim reflita sobre a sua ação pedagógica para que este novo profissional venha contribuir com um ensino de qualidade.

\section{REFERÊNCIAS:}

BRASIL. CNE/CP. N ${ }^{\circ}$ 1, DE 15 DE MAIO DE 2006. Disponível em: http://portal.mec.gov.br/cne/arquivos/pdf/rcp01_06.pdf. Acesso 19 out. 2015.

FERREIRA, José Luiz; CARVALHO, Maria Eulina Pessoa de. Gênero, masculinidade e magistério: horizontes de pesquisa. Disponível em: file:///C:/Users/joao/Downloads/14584418-1-PB\%20(1).pdf. Acesso 27 set 2016

Saberes Pedagógicos, Criciúma, v. 1, n²2, julho/dezembro 2017.- Curso de Pedagogia- UNESC 


\section{SABERES PEDAGÓGICOS}

Revista do Curso de Graduação de Pedagogia - Unesc

FORMAR. In: DICIONÁRIO da língua Portuguesa. ON-LINE. Disponível em:

http://michaelis.uol.com.br/busca?r=0\&f=0\&t=0\&palavra=formar. Acesso em 10 set. 2016.

FREIRE, Ana Maria. Concepções Orientadoras do Processo de Aprendizagem do Ensino nos Estágios Pedagógicos. Colóquio: Modelos e Práticas de formação Inicial de Professores, Faculdade de Psicologia e de Ciências da Educação, Universidade de Lisboa. Lisboa, Portugal, 2001. Disponível em: http://www.educ.fc.ul.pt/recentes/mpfip/pdfs/afreire.pdf. Acesso 03 jun. 2015.

GHEDIN, Evandro; ALMEIDA, Maria Isabel de; LEITE, Yoshie Ussami Ferrari. Formação de professores: caminhos e descaminhos da prática. Brasília: Líber Livro Editora. 2008. $142 p$.

KULCSAR, Rosa. O estágio supervisionado como atividade integradora. IN: FAZENDA, Ivani Catarina Arantes [et all]; PICONEZ, Stela C. Bertholo (Coord.). A prática de ensino e o estágio supervisionado. Campinas-SP: Papirus, 1991.

LIMA, Maria Socorro Lucena. Estágio e aprendizagem da profissão docente. Brasília, DF: Liber Livro, 2012. 171 p.

MORAES, Giselly Lima de. Estágios na licenciatura em Pedagogia: projetos de leitura e escrita nos anos iniciais. Petrópolis, RJ: Vozes; Macéio, AL: Edufal, 2012. In: CARVALHO, Mercedes; PRADO, Edna (org).

NÓVOA, António. Para uma formação de professores construída dentro da profissão. 2009. Disponível em:

http://www.revistaeducacion.educacion.es/re350/re350_09por.pdf. Acesso 15 jun 2015.

Formação de professores e profissão docente. 1992. Disponível em:

http://repositorio.ul.pt/bitstream/10451/4758/1/FPPD_A_Novoa.pdf. Acesso 15 jun 2015.

PIMENTA, Selma Garrido. O estágio na formação de professores: unidade teoria e prática. $7^{\mathrm{a}}$ ed. São Paulo: Cortez, 2005.

PIMENTA, Selma Garrido; GHEDIN, Evandro (Org.). Professor reflexivo no Brasil: gênese e crítica de um conceito. São Paulo: Cortez, 224 p.

PIMENTA, Selma Garrido; LIMA, Maria do Socorro Lucena. Estágio e docência. São Paulo: Cortez, 2004.

PINHEIRO, José Maurício dos Santos. Da iniciação científica ao TCC, uma abordagem para os cursos de tecnologia. In: Pesquisa Científica. Rio de Janeiro: Editora Ciência Moderna LTDA, 2010. p.15 a 38. 


\section{SABERES PEDAGÓGICOS}

Revista do Curso de Graduação de Pedagogia - Unesc

TARDIF, Maurice. Saberes docentes e formação profissional. Petrópolis, RJ: Vozes, 2002. $325 \mathrm{p}$.

UNESC. Regulamento de estágio do curso de Pedagogia licenciatura da Unesc. Criciúma, 2010, Disponível em:

http://www.unesc.net/portal/resources/official_documents/5166.pdf?1300279567. Acesso 15 jun 2015.

VASCONCELLOS, Celso. Metodologia dialética em sala de aula. Disponível em: http://www.celsovasconcellos.com.br/Textos/MDSA-AEC.pdf. Acesso 22 set. 2016. 